\title{
Adolescent's perceptions and expectations of parental action on children's smoking and snus use; national cross sectional data from three decades
}

\author{
Maria Nilsson*1, Lars Weinehall ${ }^{1,2}$, Erik Bergström ${ }^{1,3}$, Hans Stenlund ${ }^{1}$ and \\ Urban Janlert ${ }^{1}$
}

Address: ${ }^{1}$ Department of Public Health and Clinical Medicine, Epidemiology and Public Health Sciences, Umeå University, S-901 85 Umeå, Sweden, ${ }^{2}$ Research Department, National Institute of Public Health, S-831 40 Östersund, Sweden and ${ }^{3}$ Department of Clinical Sciences, Pediatrics, Umeå University, S-901 85 Umeå, Sweden

Email: Maria Nilsson* - maria.nilsson@epiph.umu.se; Lars Weinehall - lars.weinehall@epiph.umu.se;

Erik Bergström - erik.bergstrom@pediatri.umu.se; Hans Stenlund - hans.stenlund@epiph.umu.se; Urban Janlert - urban.janlert@epiph.umu.se

* Corresponding author

Published: 4 March 2009

BMC Public Health 2009, 9:74 doi:10.1 186/147/-2458-9-74
Received: 16 July 2008

Accepted: 4 March 2009

This article is available from: http://www.biomedcentral.com/I47I-2458/9/74

(c) 2009 Nilsson et al; licensee BioMed Central Ltd.

This is an Open Access article distributed under the terms of the Creative Commons Attribution License (http://creativecommons.org/licenses/by/2.0), which permits unrestricted use, distribution, and reproduction in any medium, provided the original work is properly cited.

\begin{abstract}
Background: Parents play a vital role as children develop tobacco behaviours. Many parents feel unsure about their possibility to influence their teenager's lifestyle. Knowledge about young people's acceptance for parental intervention could increase parental involvement. The overall objective of this study was to explore adolescents' perceptions and expectations of parental action regarding children's smoking and snus use, and whether they have changed over time. To see if there were differences whether the adolescent was a tobacco user or not the adolescents' tobacco use was followed; and described to put the findings on their perceptions and expectations of parental action in a context.
\end{abstract}

Methods: The study used a repeated cross-sectional design, reporting Swedish national data from three decades. Data were collected in 1987, 1994 and 2003 by a questionnaire mailed to homes, in total to 13500 persons. The annual samples, which were random and national representative, consisted of 4500 young people aged I 3 , 15 and 17 yr, 1500 individuals per age group. The sampling and data collection procedures were done the same way during each survey. Chi2- tests were used to evaluate differences in distributions.

Results: Adolescents in all age groups became more positive toward parental action over time. In 2003, more then $86 \%$ of the adolescents, including both smokers and non-smokers, strongly supported parental action on their children's smoking by trying to persuade them not to smoke (94\%), by not smoking themselves (87\%) and by not allowing their children to smoke at home (86\%). Both non-smokers and smokers supported the idea of parental action in a similar way. Reduced pocket money had a weak support (42\%), especially from girls. Eighty-nine percent of the adolescents expected their parents to act against smoking and $85 \%$ against snus use.

Smoking was stable at $8 \%$ in 1987 and 1994 but decreased to $4 \%$ in 2003 . In 1987 the snus use prevalence was $4 \%$ and in 2003 it was 3\%. Snus users were mostly boys while few girls had done more than tried snus. More young people in all age groups had never tried smoking compared to the previous studies. In 2003 57\% stated that they had never tried smoking. 


\begin{abstract}
Conclusion: Adolescent smoking in Sweden has decreased and the proportion who never tried smoking has increased. The results of this study show that a growing majority of adolescents support strong parental intervention to help them refrain from tobacco, but preferably not in a punitive manner. This finding dismisses the notion that adolescents ignore or even disdain parental practices concerning tobacco. Prevention strategies and interventions addressing adolescent tobacco use that involve parents can be improved by using these findings to encourage parents to intervene against their children's tobacco use.
\end{abstract}

\section{Background}

Adolescence is an important time of life for public health intervention measures, and improved actions to prevent tobacco use are vital during these years. Almost all first use of tobacco occurs before graduation from high school [1]. In a Swedish study, as many as one out of five children reports having ever used tobacco at age 11 [2]. The onset of smoking has long been described as a process that progresses through five stages from preparation, to trying, to irregular use, to regular use, and finally to nicotine dependent smoking [1,3]. Smoking addiction has been defined as smoking at least five cigarettes a day and daily smoking as a prerequisite for being nicotine dependent and experiencing withdrawal symptoms [4]. In the 1970s, Russell assumed that it took years of intermittent smoking to develop dependence with a regular adult type of smoking [5]. Recent studies have challenged these descriptions and suggested that symptoms of nicotine dependence can be found early in the smoking onset process [6-8]. DiFranza et al conclude that the most susceptible youth risk loss of their autonomy over tobacco within a day or two of first inhaling tobacco smoke [9]. Given this risk for rapid development of nicotine dependence and the modest success rates of youth cessation programmes [10], every effort should be made to keep young people from trying tobacco. To be able to model and adjust interventions, it is essential to have knowledge on adolescents tobacco use patterns: when do they start using tobacco?; how does adolescent tobacco use develop and change over time?; who can play a role in preventing adolescent tobacco use?

Young people start using tobacco in a social context where the attitudes towards tobacco, the tobacco behaviour and practices in their homes [11-13], at their schools [14,15], and in their community matter [16]. Consequently, these areas with their different participants are potentially important areas for anti-tobacco socialisation.

A vital role is played by parents as children develop tobacco behaviours. Parents can reinforce positive or negative tobacco behaviours in their child. Their smoking has a direct effect on a child's current smoking and may contribute to initiation, escalation and onset of daily smoking
$[11,13,17]$. Parental anti-smoking socialisation as a way to prevent children from starting to use tobacco has been studied in recent research. One example is the application of home smoking rules which are found to help deter adolescents from smoking [18]. Adolescents with the lowest smoking prevalence are the ones living in homes with smoking bans and in which no member ever smoked. Living in such a home, they are more likely to have quit if they are a smoker [19]. Strict home smoking rules may have an extended effect on young adults as well as on adolescents, provided that they live in parental homes [18]. The parenting style and the quality of the parent-child relationship can also affect adolescent smoking. Parental control [20] as well as parent-child connectedness [21] and parental concern [12], are important in adolescent smoking initiation. High levels of parent-child connectedness has a protective influence on youth smoking, provided the parent being a non-smoker $[22,23]$.

Parents possible impact on adolescent smoking is somewhat inconsistent with the documented view shared by many that adolescence is a time of life with decreased parental influence [24,25]. Anecdotal evidence suggests that many parents perceive others as more influential on their teenager's lifestyle, that they can not do much, and that the child does not want the parents to bother them about their smoking. If these things are believed, it could result in missed opportunities to prevent adolescent tobacco use. If it is possible to document general acceptance among young people for parental intervention, it could increase parental involvement and therefore desirable effects. To gain more knowledge on how parental practices against tobacco are perceived by the young is therefore essential to motivate hesitant parents and legitimize their actions towards tobacco use in their children.

The aim of this study was to assess adolescent's perceptions and expectations of parental action regarding children's smoking and snus use; and if they had changed over time in Sweden (1987, 1994 and 2003). The adolescents tobacco use was followed to study if there were differences whether they were tobacco users or not and to be able to put the findings on their perceptions and expectations of parental action in a context. 


\section{Methods}

The study had a repeated cross-sectional design, reporting Swedish data from three decades. In 1987, a national survey was conducted in Sweden by The National Board for Health and Welfare on young people's use of tobacco, their knowledge, attitudes and beliefs [26]. Follow up studies were carried out by The Swedish National Institute of Public Health in 1994 [27] and in 2003 [28].

There were reports before the first study stating that the majority of young people test tobacco during the first half of their teens [29]. To follow and better understand the development of tobacco use, young people aged 13, 15 and 17 were the study target group. The same three age groups were chosen for all three surveys to be able to follow trends over time.

A questionnaire was sent by post to homes each year for a sample of 4500 young people and consisted of 1500 individuals per age group. In total 13500 persons received the questionnaire. The sample was an individual random, national representative sample stratified by age drawn by Statistics Sweden [30] from the total population, ages 13, 15 and 17 years. The sampling procedure was carried out in the same way and the questionnaire was sent out at the same time of the year for each survey. By the use of an individual sampling procedure, a higher statistical power could be achieved as the cluster effects often found in school surveys were avoided. The first questionnaire was followed by two reminder letters to the non-respondents, including a new questionnaire form.

As the target group for the study was not of legal age, a letter was sent to their parents before the questionnaire was sent out to the children providing information on the study. In the letter, the parents' consent was requested using a passive consent procedure informing the parents how to proceed if they did not want their children to participate in the study. The children's right to answer the questionnaire anonymously was emphasized in the letter.

An analysis of the non-respondents was carried out by Statistics Sweden in 2003 using a calibration technique [31]. The full questionnaire was validated prior to data collection by focus group interviews with boys and girls in the same ages as in the study. Some possible validity problems were identified and the questionnaire adjusted accordingly.

In the questionnaire, the adolescents were asked questions about their personal tobacco use, if they thought that parents should try and influence their children's smoking and if their own parents had acted to prevent them from using tobacco. There were five different types of parental influence for the adolescents to respond to by answering 'yes,' 'no' or 'I don't know.' The alternatives were a) trying to persuade their children not to smoke; b) forbidding their children to smoke; c) not allowing their children to smoke at home; d) not smoking themselves; and e) reducing their children's pocket money.

\section{Definitions}

In the study, the definition of "snus" is Swedish moist snuff. When the word tobacco is used, it includes both smoking cigarettes and snus use. The following definitions were used to describe tobacco use: 1) a smoker was an occasional or a daily smoker; 2 ) an occasional smoker was smoking every week but not daily; 3 ) a daily smoker was smoking every day; 4) a non smoker had never smoked, just tried or had stopped smoking; 5) a snus user used snus ranging from <less than a box a week till $>$ than 4 boxes; 6 ) a non snus user had never used snus, had tried or had stopped using it; 7) a tobacco user was a smoker and/or a snus user.

\section{Ethics}

Ethics approval was given in 2003 by the Research Ethics Committee at Umeå University, Umeå, Sweden.

\section{Statistics}

Data were analyzed using SPSS (SPSS Inc., Chicago, IL) and Epi Info (CDC, Atlanta, GA). Differences in distributions were evaluated using Chi2-tests. A p-value of less than 0.05 was considered significant.

\section{Results}

The response rate was $67 \%$ in $1987,83 \%$ in 1994 and $66 \%$ in 2003. The analysis of the non-respondents carried out by Statistics Sweden in 2003 showed that the nonresponses could be regarded as random and most likely had not affected the results. The total number and percentages of study participants are shown in Table 1.

Table I: Study participants 1987, 1994 and 2003, reported by age and sex

\begin{tabular}{lrrrrrrr}
\hline & & boys & $\%$ & girls & $\%$ & Total & $\%$ \\
\hline 13 yr & 1987 & 480 & 64 & 451 & 60 & 931 & 62 \\
& 1994 & 617 & 82 & 667 & 89 & 1284 & 86 \\
& 2003 & 488 & 65 & 538 & 72 & 1026 & 68 \\
& & & & & & & \\
$15 y r$ & 1987 & 440 & 59 & 404 & 54 & 844 & 56 \\
& 1994 & 606 & 81 & 661 & 88 & 1267 & 84 \\
& 2003 & 456 & 61 & 512 & 68 & 968 & 65 \\
& & & & & & & \\
$17 y r$ & 1987 & 654 & 87 & 604 & 81 & 1258 & 84 \\
& 1994 & 575 & 77 & 611 & 81 & 1186 & 79 \\
& 2003 & 454 & 61 & 526 & 70 & 980 & 65 \\
\hline \multirow{2}{*}{ Total } & 1987 & 1574 & 70 & 1459 & 65 & 3033 & 67 \\
& 1994 & 1798 & 80 & 1939 & 86 & 3737 & 83 \\
& 2003 & 1398 & 62 & 1576 & 70 & 2974 & 66 \\
& & & & & & & \\
\hline
\end{tabular}




\section{Perception of parental action}

Over the three study years adolescents in all age groups became more positive toward parental actions to prevent their children from smoking $(\mathrm{p}<0.001)$. The majority of the adolescents answered that parents should try to influence their children's smoking habits, presented in table 2. The alternatives receiving the strongest adolescent support were "persuade", "not allow to smoke at home," and "not smoke themselves." More then $86 \%$ approved of all three alternatives. Support for the alternative "forbid their children to smoke" more then doubled, increasing from $26 \%$ in 1987 to $59 \%$ in 2003 ( $\mathrm{p}<0.001$ ). Weaker but increasing support was given to the alternative "reduce pocket money." This alternative was not in the questionnaire in 1987, but between 1994 and 2003, support grew from $26 \%$ to $42 \%(\mathrm{p}<0.001)$.

The results from 1987 showed that $87 \%$ of the non-smokers supported the idea that parents should try to persuade their children not to smoke. This support grew to $93 \%$ in 1994 and 95\% in 2003 ( $\mathrm{p}<0.001)$. Among smokers, this alternative was supported by $67 \%$ in 1987 and grew to $81 \%$ in 1994 and $84 \%$ in 2003 ( $\mathrm{p}<0.001$ ). For the alternatives "forbid children to smoke" and "reduce children's pocket money," smokers gave much weaker support then non-smokers. The support for parental action against children's smoking was stronger amongst non-smokers ( $\mathrm{p}<$ 0.001 ) but both non-smokers and smokers supported the idea in a similar way.
Statistically significant age differences were found for the alternatives "persuade," "forbid," and "reducing pocket money," with the strongest support from 13 year olds ( $\mathrm{p}$ $<0.001)$. No age differences were found for "not allowing the children to smoke at home" and "by parents not smoking themselves." Boys were more positive then girls about the alternatives "forbid" and "reducing pocket money" (p < 0.001).

A majority of the adolescents answered that their parents would try to make them stop if they started smoking or using snus. Eighty-nine percent said that their parents would try to make them stop smoking. The non-smokers were more convinced of parental action then the smokers. Among the smokers, $71 \%$ reported that their parents would try to persuade them to stop whilst $4 \%$ said that their parents would not care about their smoking. Sixtyseven percent of the smokers said that they would be influenced by their parents not wanting them to smoke, and out of those, $30 \%$ said that it would influence them a lot.

Considering snus use, $85 \%$ expected their parents to act. It was statistically significant that the non snus users expected this to a greater extent then the snus users. But while $71 \%$ of the smokers' parents tried to persuade them to quit, only $36 \%$ of the snus users had experienced this parental action. Twenty-two percent of the snus users said that their parents did not care about their snus use.

Table 2: Adolescent's perceptions of parental practices on children's smoking.

\begin{tabular}{|c|c|c|c|c|c|}
\hline & & $13 \mathrm{yr}$ & $15 \mathrm{yr}$ & $17 \mathrm{yr}$ & Total \\
\hline \multirow[t]{3}{*}{ By trying to persuade their children not to smoke } & 1987 & 92 & 86 & 79 & 86 \\
\hline & 1994 & 94 & 90 & 89 & 91 \\
\hline & 2003 & 96 & 93 & 92 & 94 \\
\hline \multirow[t]{3}{*}{ By not smoking themselves } & 1987 & 86 & 86 & 86 & 86 \\
\hline & 1994 & 86 & 86 & 89 & 87 \\
\hline & 2003 & 88 & 86 & 88 & 87 \\
\hline \multirow[t]{3}{*}{ By not allowing the children to smoke at home } & 1987 & 63 & 64 & 59 & 62 \\
\hline & 1994 & 84 & 82 & 76 & 81 \\
\hline & 2003 & 87 & 87 & 84 & 86 \\
\hline \multirow[t]{3}{*}{ By forbidding their children to smoke } & 1987 & 45 & 22 & 12 & 26 \\
\hline & 1994 & 54 & 33 & 23 & 37 \\
\hline & 2003 & 76 & 58 & 44 & 59 \\
\hline \multirow[t]{3}{*}{ By reducing their children's pocket money* } & 1987 & - & - & - & - \\
\hline & 1994 & 37 & 23 & 17 & 26 \\
\hline & 2003 & 53 & 39 & 32 & 42 \\
\hline
\end{tabular}

Adolescents answering yes in percent, by age, survey year and order of precedence.

All differences over time are statistically significant $p<0.001$, with the exception of alternative "By not smoking themselves" with $p=0.038$

$*$ The alternative was not in the 1987 questionnaire 


\section{Smoking and snus use}

Smoking prevalence was stable at 8\% in 1987 and 1994 but decreased to $4 \%$ in 2003 ( $\mathrm{p}<0.001$ ), the decrease was found in both girls and boys. In 2003, more young people in all age groups had never tried smoking compared to the previous years studied ( $\mathrm{p}<0.001$ ). In total, 57\% stated that they had never tried smoking; $58 \%$ of boys and $56 \%$ of girls. The smoking prevalences are shown in table 3 .

The smoking pattern changed with age. Almost all 13 year olds were smoke free; 3\% reported smoking and more than $75 \%$ said that they had never tried smoking. At age $15,4 \%$ of boys and $11 \%$ of girls smoked while more then $50 \%$ reported never having smoked. At age 17, 14\% of boys and $21 \%$ of girls smoked and more then $35 \%$ had never tried smoking. For all three study years, more girls than boys were daily smokers $(\mathrm{p}<0.001)$.

Smoking prevalence was lower in 2003 compared to the previous years but there was no corresponding change in snus use. A decrease in snus use was noted among boys from 1987 to 1994 ( $\mathrm{p}<0.01$ ), but there was no difference between 1994 and 2003.

Snus users were mostly boys while few girls had done more than tried snus. Similar to smoking, snus use also increased with age. The snus use prevalence is presented in table 4. Amongst the boys there was a group that both smoked and used snus, 4\% in 1994 and 3\% in 2003.

\section{Discussion}

Studies on adolescents' perceptions of parental actions against their children's tobacco use are rare. In a North American study, adolescents significantly legitimized parent authority to a greater extent for tobacco and alcohol than for conventional and contemporary issues (ie, religion, education, music, clothing) [32]. In the present study, among both smokers and non-smokers, support for parental action against their children's smoking or snus use is substantial and has grown over time. In 2003, $94 \%$ supported the concept that parents should try to persuade their children not to smoke, $87 \%$ agreed that parents should influence children by not smoking themselves, and $86 \%$ thought children should not be allowed to smoke at home. The three alternatives most strongly supported by the young people represent examples of intervention components that have been found fruitful in adolescent smoking prevention research. The alternative receiving the least support was the reduction of pocket money, and this was more pronounced among the smokers. This corresponds with some recent research suggesting caution in using suppressing control and strictness as they do not have any effect in prevention of smoking uptake [13]. Smoking-specific punishments by parents who smoke themselves are even suggested to increase the risk of smoking escalation among adolescents [33]. The introduction of the tobacco legislation and public discussions can be assumed to influence young people so that they have become more positive towards steps taken to prevent or obstruct their use of tobacco.

Table 3: Adolescent smoking in 1987, 1994 and 2003, in percent by sex and age

\begin{tabular}{|c|c|c|c|c|c|c|c|c|c|}
\hline & & \multicolumn{2}{|c|}{$13 \mathrm{yr} \%$} & \multicolumn{2}{|c|}{15 yr \% } & \multicolumn{2}{|c|}{17 yr \% } & \multicolumn{2}{|c|}{ Total $\%$ and $(\mathrm{N})$} \\
\hline & & Boys & Girls & Boys & Girls & Boys & Girls & Boys & Girls \\
\hline \multirow[t]{3}{*}{ Have never tried } & 1987 & 61 & 68 & 39 & 42 & 30 & 26 & $42(658)$ & $43(628)$ \\
\hline & 1994 & 55 & 60 & 37 & 34 & 29 & 23 & 41 (733) & $39(762)$ \\
\hline & 2003 & 77 & 76 & 57 & 56 & 36 & 35 & $58(797)^{*}$ & $56(874)^{*}$ \\
\hline \multirow[t]{3}{*}{ Have tried } & 1987 & 35 & 28 & 48 & 35 & 45 & 40 & $43(672)$ & $36(5 \mid 3)$ \\
\hline & 1994 & 38 & 33 & 45 & 37 & 44 & 40 & $42(757)$ & 37 (709) \\
\hline & 2003 & 21 & 19 & 35 & 30 & 45 & 36 & $33(462)$ & $29(448)$ \\
\hline \multirow[t]{3}{*}{ Have smoked but stopped } & 1987 & 2 & 1 & 3 & 2 & 3 & 3 & $2(40)$ & $2(3 I)$ \\
\hline & 1994 & 3 & 3 & 5 & 6 & 6 & 7 & $5(80)$ & $5(101)$ \\
\hline & 2003 & I & 1 & 4 & 3 & 5 & 8 & $3(46)$ & $4(63)$ \\
\hline \multirow[t]{3}{*}{ Smoke occasionally } & 1987 & 2 & 3 & 7 & 13 & 11 & 14 & 7 (108) & $10(144)$ \\
\hline & 1994 & 2 & 3 & 7 & 12 & 10 & 10 & $6(110)$ & $9(162)$ \\
\hline & 2003 & I & 2 & 2 & 5 & 9 & 9 & $4(54)^{*}$ & $5(84)^{*}$ \\
\hline \multirow[t]{3}{*}{ Smoke every day } & 1987 & 0 & 0 & 3 & 8 & II & 17 & $6(87)$ & $9(132)$ \\
\hline & 1994 & 2 & 1 & 6 & II & 11 & 20 & $6(113)$ & $10(198)$ \\
\hline & 2003 & 0 & 2 & 2 & 6 & 5 & 12 & $2(3 I)^{*}$ & $6(102)^{*}$ \\
\hline
\end{tabular}

The results marked * are the statistically significant results (with $\mathrm{p}<0.00 \mathrm{I}$ ) stated and discussed in the paper 
Table 4: Adolescent snus use in 1987, 1994 and 2003, in percent by sex and age

\begin{tabular}{|c|c|c|c|c|c|c|c|c|c|}
\hline & & \multicolumn{2}{|c|}{$13 \mathrm{yr} \%$} & \multicolumn{2}{|c|}{$15 \mathrm{yr} \%$} & \multicolumn{2}{|c|}{$17 \mathrm{yr} \%$} & \multicolumn{2}{|c|}{ Total \% and $(\mathrm{N})$} \\
\hline & & Boys & Girls & Boys & Girls & Boys & Girls & Boys & Girls \\
\hline \multirow[t]{3}{*}{ Have never tried } & 1987 & 74 & 92 & 47 & 79 & 34 & 65 & $50(780)$ & $77(1118)$ \\
\hline & 1994 & 77 & 93 & 49 & 78 & 39 & 66 & 56 (989) & $80(1519)$ \\
\hline & 2003 & 82 & 92 & 59 & 80 & 48 & 60 & $64(882)$ & $77(1213)$ \\
\hline \multirow[t]{3}{*}{ Have tried } & 1987 & 21 & 8 & 35 & 19 & 38 & 32 & $32(504)$ & $21(305)$ \\
\hline & 1994 & 20 & 7 & 36 & 22 & 34 & 32 & $30(534)$ & $19(383)$ \\
\hline & 2003 & 15 & 8 & 29 & 19 & 30 & 35 & $25(335)$ & $20(319)$ \\
\hline \multirow[t]{3}{*}{ Have used snus but stopped } & 1987 & 2 & 0 & 5 & 2 & 5 & I & $4(60)$ & $\mathrm{I}(\mathrm{II})$ \\
\hline & 1994 & I & 0 & 3 & 0 & 6 & I & $3(55)$ & $0(6)$ \\
\hline & 2003 & 1 & 0 & 2 & I & 3 & I & $2(31)$ & $I(13)$ \\
\hline \multirow[t]{3}{*}{ Use less then one box/week } & 1987 & 2 & 0 & 3 & 0 & 5 & I & $4(58)$ & $0(5)$ \\
\hline & 1994 & I & 0 & 5 & 0 & 3 & I & $3(5 \mathrm{I})^{*}$ & $1(19)$ \\
\hline & 2003 & 1 & 0 & 2 & 0 & 2 & 1 & $1(19)$ & $I(10)$ \\
\hline \multirow[t]{3}{*}{ Use one box or more/week } & 1987 & I & 0 & 10 & 0 & 18 & I & $10(164)$ & I (9) \\
\hline & 1994 & I & 0 & 7 & 0 & 18 & 0 & $8(151)^{*}$ & $0(5)$ \\
\hline & 2003 & I & 0 & 8 & 0 & 17 & 3 & $8(117)$ & I (16) \\
\hline
\end{tabular}

The results marked $*$ are the statistically significant results (with $\mathrm{p}<0.0 \mathrm{I}$ ) stated and discussed in the paper

Darling and Steinberg have demonstrated as part of their theoretical work that adolescents' adjustment varies as a function of their parents' style and suggested that openness to parental influence is important for prediction of outcomes in adolescents [34]. If so, there is a golden opportunity for successful prevention efforts involving parents. A high proportion of the adolescents support parental action to keep them from tobacco use and this can be assumed to make them more open to their parents' influence. Research has shown that parents' anti-smoking socialisation can prevent children from using tobacco [1823].

A majority of the adolescents surveyed in 2003 said that their parents would try to make them stop if they started using tobacco. The non-tobacco users were more convinced of parental action then were the tobacco users. It was more common that tobacco using adolescents had tobacco using parents, and this may be one of the explanations for this finding. Parents using tobacco are modelling tobacco use and might also find it difficult to practice anti-tobacco socialisation in a consequential manner.

In this study it was much more common that young smokers than young snus users expected their parents to make their child quit. A larger proportion of snus users said that their parents would not care about their child's snus use. Even if there is growing scientific evidence of negative health effects from Swedish snus use, people often tend to compare it with health effects from smoking. In that comparison anything seems less harmful, and this might explain the more passive stand taken by snus users' parents.

With data from three decades, this study demonstrates that smoking has decreased among Swedish adolescents over the studied years. An even larger decrease has been reported in the Swedish adult population [35]. The number of adolescents who had never tried tobacco increased over the studied years. There was also a decrease in adolescent snus use noted. Some have suggested snus use as an explanation for decreased smoking prevalence in Sweden. This study does not support such a conclusion. In a study of Swedish adolescents Galanti et al concluded that snus use in adolescence did not substitute smoking and that the availability of snus might increase nicotine addiction in vulnerable subgroups [36]. In their study as well as in ours the proportion of girls using snus was very low and the results therefore confined to boys snus use. The explanation for the decrease in smoking among adolescents is probably multi-factorial. The first Swedish tobacco legislation with regulations on smoke free environments was introduced in 1993 and made more stringent in 1994. Legislation prohibiting tobacco sales to minors was introduced in 1997 [37]. The legislation, the increased tobacco taxation together with other national tobacco control efforts, and the influence of public opinion probably decreased the social acceptance for smoking and contributed to this reduction in youth smoking. An important societal determinant for smoking is the social acceptance of smoking. A low social acceptance can be assumed to be an important reason for parents wanting to 
intervene against their children smoking, in particular for parents who smoke themselves.

In $2003,3 \%$ reported being a smoker at age 13 . Thus, to prevent tobacco initiation and escalation one will have to pay attention to children's attitudes towards tobacco and early experimentation. This must be done before they enter their teens. The research findings suggesting a risk for rapid development of nicotine dependence early in smoking onset [6-8] stresses the importance of early prevention measures aimed at "not even trying tobacco." It is essential that parents and others who want to intervene are aware of this information.

While smoking decreased during the study, snus use was stable. More boys than girls used snus while more girls were daily smokers. It should be noted that the same gender pattern is seen in adults [35]. Adults, including parents, serve as models for young people in tobacco use [13].

The reports were confined to adolescents reporting about how parents would act if their children used tobacco. Their answers revealed a positive expectation about parental engagement, an expectation that in itself can affect them positively. A limitation of the study was that the sample sizes were too small to include enough girl snus users to be able to draw valid conclusions about girls snus use. A strength of the study was that data were collected over three decades in a manner that allowed comparisons over time. Other strengths were the validation of the questionnaire prior to implementation of the survey and the analysis of non-respondents.

\section{Conclusion}

The results of this study contradict the perception often expressed by parents that their teenage children do not want them to intervene and that they have lost the possibility of influencing their children's lifestyles, including the use of tobacco. This study shows that a majority of adolescents strongly support that their parents should intervene to help them refrain from tobacco, but preferably not in a punitive manner. This support includes both non tobacco and tobacco using adolescents. The finding rejects the notion that adolescents ignore or even despise parental practices concerning tobacco. Prevention strategies and interventions addressing adolescent tobacco use that involve parents can be improved by using these findings to motivate and encourage parents to be active and to intervene against their children's use of tobacco.

\section{Competing interests}

The authors declare that they have no competing interests.

\section{Authors' contributions}

$\mathrm{MN}$ was the main author of the manuscript and involved in all aspects of the study. LW, EB, HS and UB provided scientific oversight and feedback throughout the development of the study and the manuscript. All co-authors have seen and approved the final version of the paper and have agreed to its submission for publication.

\section{Acknowledgements}

Funding from Västerbotten County Council, Umeå, Sweden and the Swedish National Public Health Institute, Stockholm, Sweden, supported research for this article.

\section{References}

I. US Department of Health and Human Services: Preventing tobacco use among young people. A report of the Surgeon General Atlanta, Georgia: Public Health Service, Center for Disease Control and Prevention, Office on Smoking and Health, (US Government Printing Office Publication No S/N 0 I7-00I-0049I-0.); 1994.

2. Galanti MR, Rosendahl I, Post A, Gilljam H: Early gender differences in adolescent tobacco use - The experience of a Swedish cohort. Scand J Public Health 200I, 29:3 I4-3I7.

3. Mayhew KP, Flay BR, Mott JA: Stages in the development of adolescent smoking. Drug Alcohol Depend 2000, 59:6I-8I.

4. Benowitz NL, Henningfield JE: Establishing a nicotine threshold for addiction. N Engl J Med |994, 33 I: |23-| 25.

5. Russell MA: Cigarette smoking: Natural history of a dependence disorder. Br J Med Psychol I97I, 44:I-16.

6. Gervais A, O'Loughlin J, Meshefedjian G, Bancej C, Tremblay M: Milestones in the natural course of onset of cigarette use among adolescents. CMAJ 2006, I 75:255-26I.

7. DiFranza JR, Savageau JA, Rigotti NA, Fletcher K, Ockene JK, McNeill $A D$, Coleman M, Wood C: Development of symptoms of tobacco dependence in youths: $\mathbf{3 0}$ month follow up data from the DANDY study. Tob Control 2002, I I:228-235.

8. Wellman RJ, DiFranza JR, Savageau JA, Dussault GF: Short term patterns of early smoking acquisition. Tob Control 2004, I 3:25 I-257.

9. DiFranza JR, Savageau JA, Fletcher K, O'Loughlin J, Pbert L, Ockene JK, McNeill AD, Hazelton J, Friedman K, Dussault G, et al.: Symptoms of Tobacco Dependence After Brief Intermittent Use2 study. Arch Pediatr Adolesc Med 2007, I 6 I:704-710.

10. Sussman S: Effects of sixty six adolescent tobacco use cessation trials and seventeen prospective studies of self-initiated quitting. TID 2002, I:35-8I.

II. Hill KG, Hawkins JD, Catalano RF, Abbott RD, Guo J: Family influences on the risk of daily smoking initiation. J Adolesc Health 2005, 37:202-210.

12. Kalesan B, Stine J, Alberg AJ: The joint influence of parental modelling and positive parental concern on cigarette smoking in middle and high school students. J Sch Health 2006, 76:402-407.

13. Harakeh Z, Scholte R, Vermulst A: Parental factors and adolescents' smoking behaviour: an extension of the theory of planned behaviour. Prev Med 2004, 39:95I-96I.

14. Aveyard P, Markham WA, Cheng KK: A methodological and substantive review of the evidence that schools cause pupils to smoke. Soc Sci Med 2004, 58:2253-2265.

15. Wold B, Torsheim T, Currie C, Roberts C: National and school policies on restrictions of teacher smoking: a multilevel analysis of student exposure to teacher smoking in seven European countries. Health Educ Res 2004, 19:217-226.

16. Wakefield MA, Chaloupka FJ, Kaufman NJ, Orleans CT, Barker DC, Ruel EE: Effect of restrictions on smoking at home, at school, and in public places on teenage smoking: cross sectional study. BMJ 2000, 321:333-337.

17. Bricker JB, Peterson AV Jr, Leroux BG, Andersen MR, Rajan KB, Sarason IG: Prospective prediction of children's smoking transitions: role of parents' and older siblings' smoking. Addiction 2006, I 0 I:I28-136. 
18. Clark PI, Schooley MW, Pierce B, Schulman J, Hartman AM, Schmitt $C L$ : Impact of home smoking rules on smoking patterns among adolescents and young adults. Prev Chronic Dis 2006, 3(2A4I [http://www.cdc.gov/pcd/issues/2006/apr/05 0028.htm]. Epub 2006 Mar 15

19. Farkas AJ, Gilpin EA, White MM, Pierce JP: Association between household and workplace smoking restrictions and adolescent smoking. JAMA 2000, 284:7I7-722.

20. den Exter Blokland EA, Hale WW 3rd, Meeus W, Engels RC: Parental support and control and early adolescent smoking: $A$ longitudinal study. Subst Use Misuse 2007, 42:2223-2232.

21. Karcher MJ, Finn L: How connectedness contributes to experimental smoking among rural youth: Developmental and ecological analyses. J Prim Prev 2005, 26:25-36.

22. Fleming $\mathrm{CB}, \mathrm{Kim} \mathrm{H}$, Harachi TW, Catalano RF: Family processes for children in early elementary school as predictors of smoking initiation. J Adolesc Health 2002, 30:184-189.

23. Tilson EC, McBride CM, Lipkus IM, Catalano RF: Testing the interaction between parent-child relationship factors and parent smoking to predict youth smoking. J Adolesc Health 2004, 35:182-189.

24. Krosnick JA, Judd CM: Transitions in social influences at adolescence: who induces cigarette smoking? Developmental Psychology 1982, 18:359-68.

25. Perry CL, Kelder SH, Komro KA: The social world of adolescents: family, peers, schools and the community. In Promoting the health of adolescents: new directions for the twenty-first century New York, NY: Oxford Univ. Press; 1993.

26. Marklund U: Det onda jag inte vill det gör jag. En kartläggning av 13-I7 åringars tobaksvanor, kunskaper och attityder Stockholm, Sweden: SoSrapport; 1989:6.

27. Marklund U, och Törnell B: Svenska tonåringars tobaksvanor, kunskaper och attityder 1987 och 1994 Stockholm, Sweden: Swedish National Institute of Public Health; 1996:97.

28. Nilsson M: Tonåringar om tobak -vanor, kunskaper och attityder Stockholm, Sweden: Swedish National Institute of Public Health; 2005:32.

29. Skolelevers drogvanor 1986-87. Stockholm, Sweden: CAN rapport nr 51987.

30. Statistics Sweden 1987 [http://www.scb.se/default 2154.aspx]

31. Lundström S: Calibration as a standard method for treatment of non response. In $\mathrm{PhD}$ thesis Stockholm University, Department of Statistics; | 997. ISBN 9|-7|53-64|-8

32. Jackson C: Perceived legitimacy of parental authority and tobacco and alcohol use during early adolescence. J Adolesc Health 2002, 3 I :425-432.

33. Chassin L, Presson CC, Rose J, Sherman SJ, Davis MJ, Gonzalez JL: Parenting style and smoking-specific parenting practices as predictors of adolescent smoking onset. J Pediatr Psychol 2005, 30:333-344.

34. Darling N, Steinberg L: Parenting style as context: an integrative model. Child Dev 1993, I I3:487-496.

35. Statistics Sweden, Living Conditions Survey (ULF) [http:www.scb.se/ PageProduct 12187.aspx?Produktkod=LE0 I0I \&displaypublica tions=true]

36. Galanti MR, Wickholm S, Gilljam $\mathrm{H}$ : Between harm and dangers. Eur J Public Health 200 I, I I:340-345.

37. Government Offices of Sweden, Ministry of Health and Social Affairs Cornerstones of the Swedish tobacco policy [http:// www.sweden.gov.se/sb/d/5628].

\section{Pre-publication history}

The pre-publication history for this paper can be accessed here:

http://www.biomedcentral.com/1471-2458/9/74/prepub
Publish with Bio Med Central and every scientist can read your work free of charge

"BioMed Central will be the most significant development for disseminating the results of biomedical research in our lifetime. "

Sir Paul Nurse, Cancer Research UK

Your research papers will be:

- available free of charge to the entire biomedical community

- peer reviewed and published immediately upon acceptance

- cited in PubMed and archived on PubMed Central

- yours - you keep the copyright
BioMedcentral 